\title{
Adult Immunization
}

The proposed Comprehensive Child Immunization Act of 1993 would have government be the sole purchaser for childhood vaccines. The President of the American Academy of Pediatrics has praised the legislation as addressing the fact that "...the immunization rate for preschool children is abysmal, nationally probably less than 50\%." At last years's EIS Conference, a paper described the situation for adults over the age of 65 ; only $30 \%$ were immunized against influenza each year. Some of the efforts of the Influenza and Pneumonia Action
Group (IPAG), convened in 1989 by the National Coalition for Adult Immunization (NCAI), were described in a recent issue of M M WR (41:772-5). The difficulties in implementing vaccination programs for adults were well covered in this article. With a comprehensive proposal likely to emerge from the President's Task Force on National Healthcare Reform this month, SHEA members may wish to be proactive in addressing the current underutilization of vaccines for adults, including influenza and pneumonia. In the next few months, the editors would like to share success stories called to our attention that have addressed, in local hospitals or healthcare systems, the systematic barriers that continue to impede progress toward the national health objectives for immunization by the year 2000. These objectives include ..."increasing to $60 \%$ the proportion of older and chronically ill noninstitutionalized persons who are vaccinated against pneumococcal and influenza infections."

\section{Implementing the use of safer needles}

The editors of SHEA News would like to call to the attention of our readers the publication "Implementing Safer Needle Devices," Item No. 196310, available from the American Hospital Association (phone 800-242-2626). With the Occupational Safety and Health Administration's final standard on bloodborne pathogens calling for hospitals to "...evaluate and adopt engineering controls...," this well-written document details the background that has generated the momentum for development of safer needle devices and provides guidance for their evaluation and adoption. Its bibliography is current through 1992. The appendices include a description of the Centers for Disease Control and Prevention and the Food and Drug Administration's surveillance systems on occupational exposures to HIV, particularly as they relate to medical devices, and several case studies in hospitals that investigated the problems

Brief items of interest for the SHEA N ews or N ewsletter may be sent to C. Glen Mayhall, MD, SHEA, Newsletter Editor, Division of Infectious Diseases, D epartment of M edicine, U niversity of Tennessee, M emphis, 956 Court A ve., M emphis, TN 38163; FAX (901) 528-5854. Copy should be typed, double-spaced, and should not exceed five pages. 